\title{
Parameter Analysis of CNTFET
}

\author{
Anitha N, Srividya $\mathbf{P}$
}

\begin{abstract}
In this paper, a parameter analysis of CNTFET is presented with different parameters variations such as gate to source voltage $v_{g s}$, oxide thickness $t_{o x}$ gate oxide dielectric $K_{o x}$, channel length $L$, source/drain spacer dielectric constant $K_{\text {spa }}$ ect. All the parameters of CNTFET have been varied in CADENCE Virtuoso environment and verified with the preferred value of stanford VS-CNTFET model.
\end{abstract}

Index Terms: GAA-CNTFET, source to drain tunneling mode, band to band tunneling mode

\section{INTRODUCTION}

Recent application of transistors in the field of computer technology and electronics require size reduction. Apart from size reduction, it is also required to build devices which consumes lesser power and exhibit better electronic properties and results in high speed operation. Unfortunately there are some problems emerging when the size of the fabricated transistor shrink. The smaller size of doped regions can lead to tunneling electron flow from one electrode to the other resulting in reduced ability to control. In a device with very large transistor density electron tunneling effect causes crosstalk between transistors built next to each other. Further progress of scaling to increase the integration will be hindered by many problems such as drain induced barrier lowering, threshold voltage roll off, exponential increase in leakage current and many more To avoid the above mentioned problems, the new approach carbon nanotube technology is introduced which is used to design transistor called carbon nano tube field effect transistor (CNTFET) which is the replacement of CMOS FET. Using carbon nanotube technology [1], above mentioned problems can be avoided and high speed and low power can be achieved by designing the digital circuits with miniaturization.

Revised Manuscript Received on 30 July 2019

* Correspondence Author

Anitha N*, Department of Electronics \& Communication Engineering, Amruta Institute of Engineering \& management Sciences, Bidadi, Karnataka, India.

Dr.Srividya P, Department of Electronics \& Communication Engineering, R V College of Engineering, Bangalore, India.

(C) The Authors. Published by Blue Eyes Intelligence Engineering and Sciences Publication (BEIESP). This is an open access article under the CC-BY-NC-ND license http://creativecommons.org/licenses/by-nc-nd/4.0/

\section{LITERATURE REVIEW}

A. Carbon nano tube

Carbon nanotube in theoretical definition is a graphite sheets rolled up along a wrapping vector. Fig. 1 shows the cylindrical structure of CNTFET

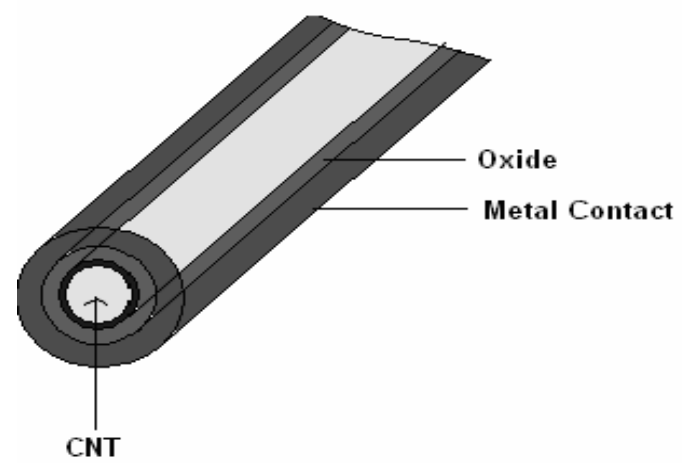

Fig. 1 Structure of cylindrical CNTFET

There are two types of classification in CNTFET

- $\quad$ Single-walled nanotubes (SWNTS)

- Multi-walled nanotubes (MWNTS)

A single-walled carbon nanotube is made by one layer of graphite. Fig 2(a) shows the Single-walled carbon nanotube. Most of the cases single walled nanotubes are employed due to its electronics properties which are not there in the multi-walled nanotubes.

Fig 2(b) shows Multi-walled carbon nanotubes. The graphite sheets are rolled up in multi-walled nanotubes like rolled news paper. The ability of telescopic motion of inner shells and the mechanical properties promises the multi-walled tubes are future adaptable mechanical devices.

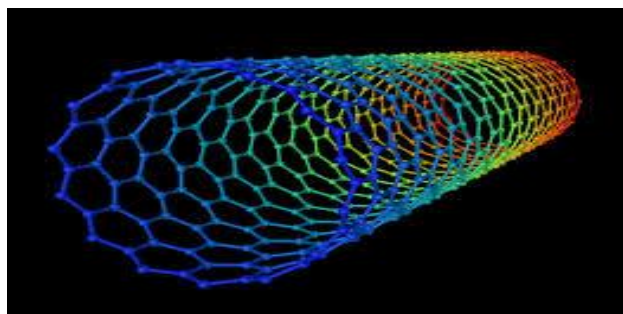

Fig. 2(a). Single walled carbon nanotubes 


\section{Parameter Analysis of CNTFET}

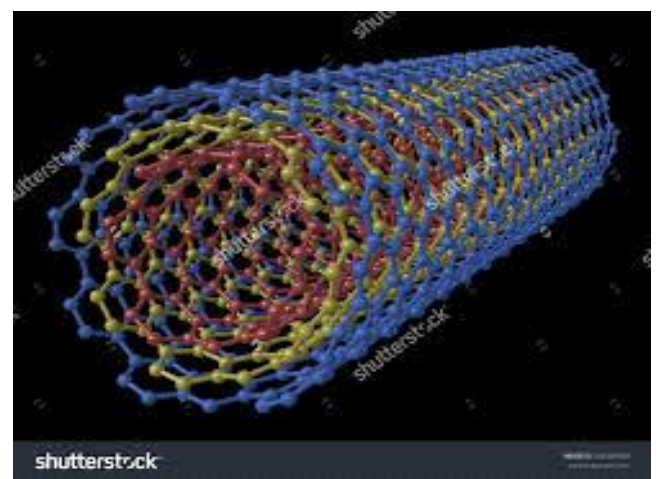

Fig. 2(b) Multi-walled carbon nanotubes
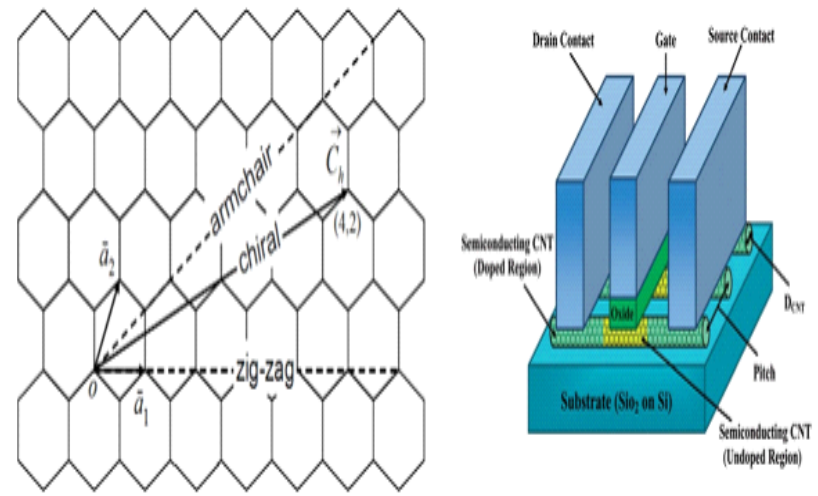

Fig.3(a) Representation of a SWNT, Fig.3(b) Schematic of CNFET

Single walled nano tube is shown in fig. 3(a). There are three types of single walled nano tubes depends on chiral vector[2]. The diameter of nanotube $\left(D_{\mathrm{cnt}}\right)$ is given by Equation (1).

$$
\begin{gathered}
D_{C N T}=\frac{0.249 \sqrt{n_{1}^{2}+n_{2}^{2}+n_{1} n_{2}}}{\pi} \\
V_{t h} \approx \frac{E_{g}}{2 . e}, \quad E_{g}=\frac{2 \sqrt{3}}{3} \frac{a \cdot V_{\pi}}{D_{c n t}} \\
\Rightarrow V_{t h} \approx \frac{\sqrt{3}}{3} \frac{a \cdot V_{\pi}}{e D_{c n t}} \approx \frac{0.43}{D_{c n t}(\mathrm{~nm})}
\end{gathered}
$$

Where parameter $E_{g}$ is the band gap energy, parameter a $(\approx 0.249 \mathrm{~nm})$ is the carbon-to-carbon atom distance, $\mathrm{V}_{\pi}$ is $(\approx 3.033 \mathrm{eV}$ ) the carbon $\pi-\pi$ bond energy, $\mathrm{e}$ is the unit electron charge and $\mathrm{D}_{\mathrm{cnt}}$ is the diameter of CNT.

By equation (1) and (2), the diameter of the CNT is inversely proportional to the threshold voltage. Hence by changing the diameter of nanotubes threshold voltage can controlled.

\section{B. Characteristics of CNTFET}

1. To achieve the low power dissipation and delay reduction in digital circuits, CNTFET model is used which is applicable only to MOSFET like CNTFETs.

2. The typical CNFET structure modeled is shown in Fig. 4, In this gate all around CNTs are placed on the silicon substrate and gate are extended to the heavily doped source/drain [3]. There is no body effect in this model, because CNTs are sit on thick silicon dioxide. Hence there are three terminals in this model named as drain, source and gate. Vgs(i) and Vds(i) represents the gate to internal source and internal drain voltage respectively. The V-I characteristics of the $p$ type and $n$ type CNTFETs are symmetric due to the symmetry of the CNTs conduction and valance band.

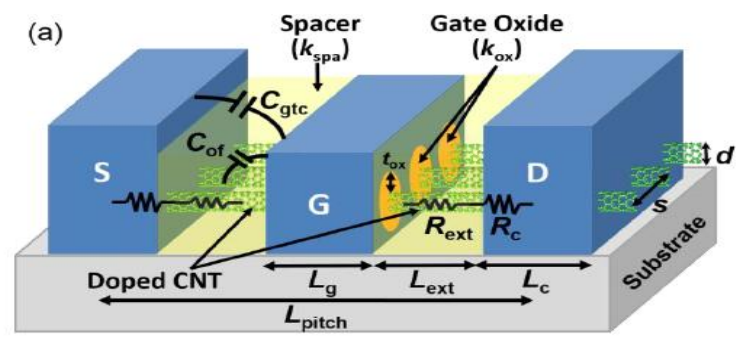

Fig. 4: VS-CNTFET Model

\section{User-Defined Input Parameters of VS-CNTFET}

The Inputs parameters of VS-CNTFET are gate length $(L g)$, contact length $(L c)$, CNT diameters $(d)$, and gate oxide thickness (tox), gate oxide dielectric constant Kox, substrate dielectric constant Ksub, source/drain spacer dielectric constant Kspa, Fermi level to band edge (ev) at the source/drain, rated to the doping density Efsd, flat band voltage (V) Vfb, Contact mode Rcmod, User defined series resistance $(\Omega)$ Rs0, Source to drain tunnelling mode STDmod, band to band tunnelling mode BTBTmod.

Device is tested for the various input parameters which are mentioned above. Fig. 5 shows the circuit diagram for the characteristic analysis of CNTFET.

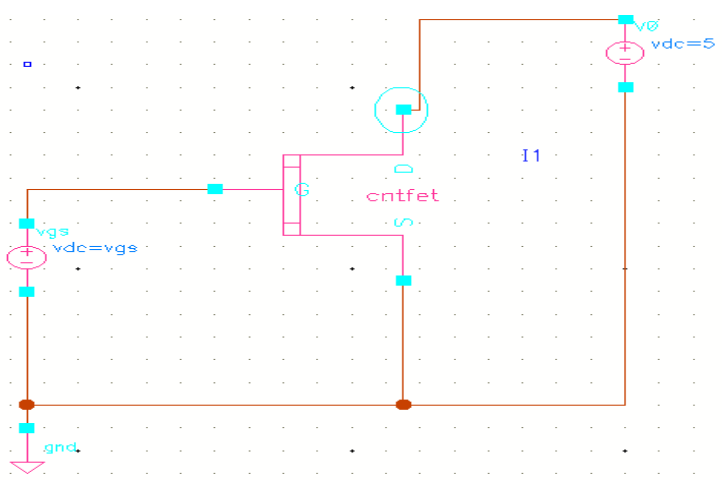

Fig. 5 Circuit Diagram For CNTFET Parameter Analysis.

The simulated results shown in fig. 6(a) to 6(l).

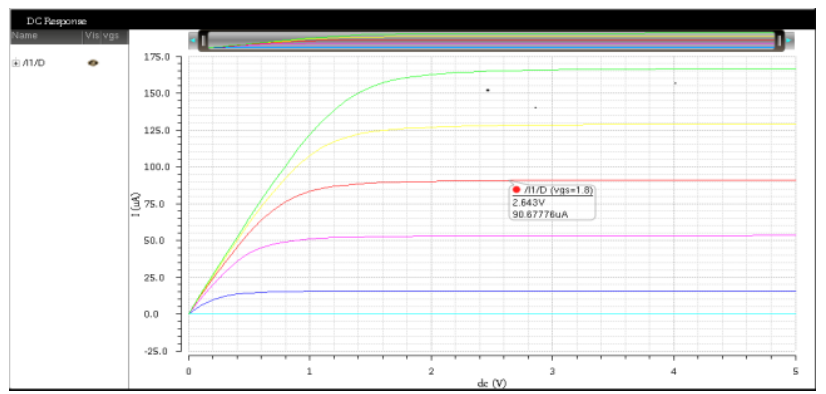

Fig. 6(a) Variation of current conduction with $V_{g s}$ 


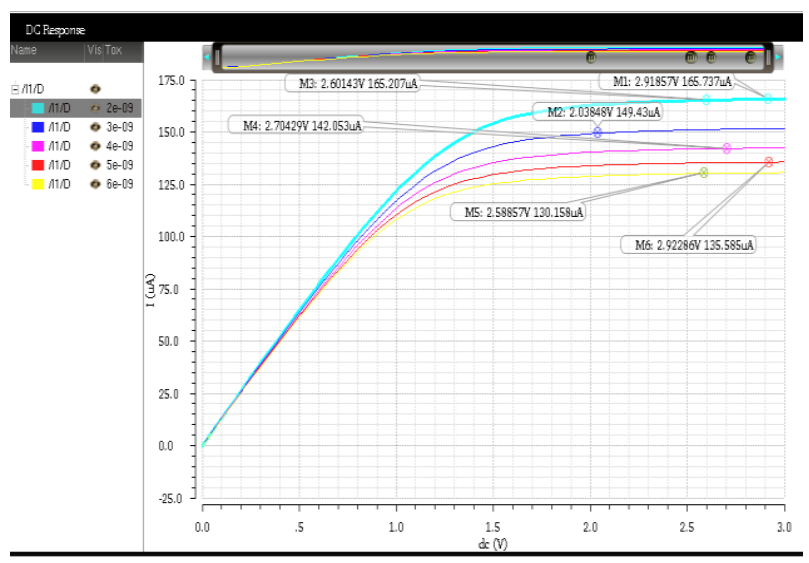

Fig. 6(b) Variation of current conduction with $t_{0 x}$

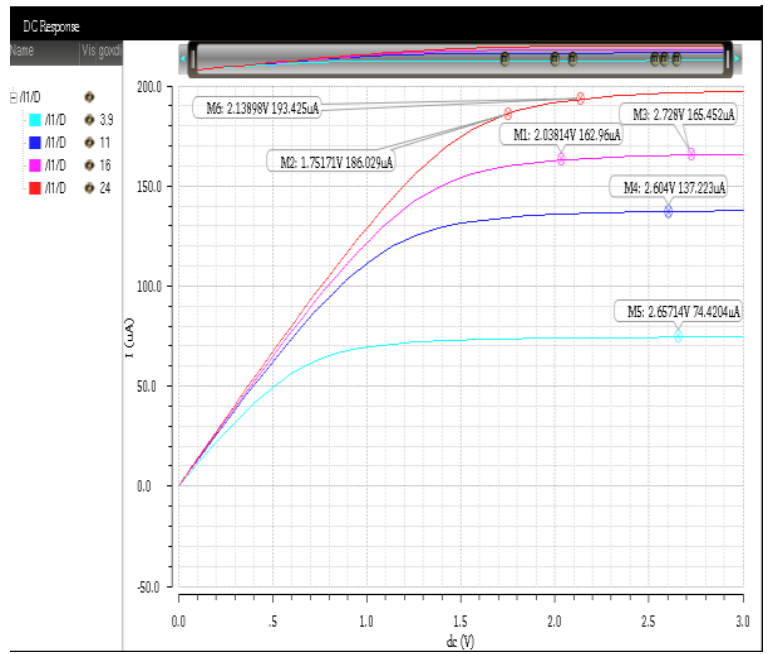

Fig. 6(c) Variation of current conduction with gate oxide dielectric.

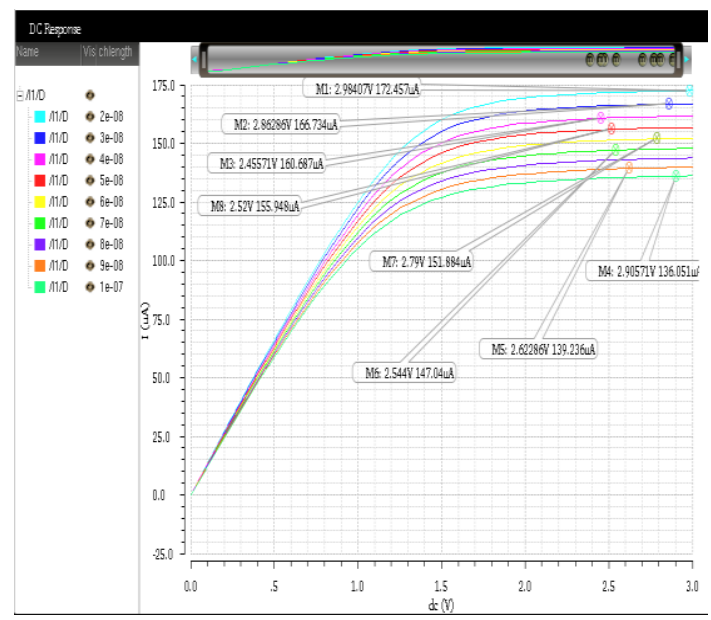

Fig. 6(d) Variation of current conduction with Channel Length

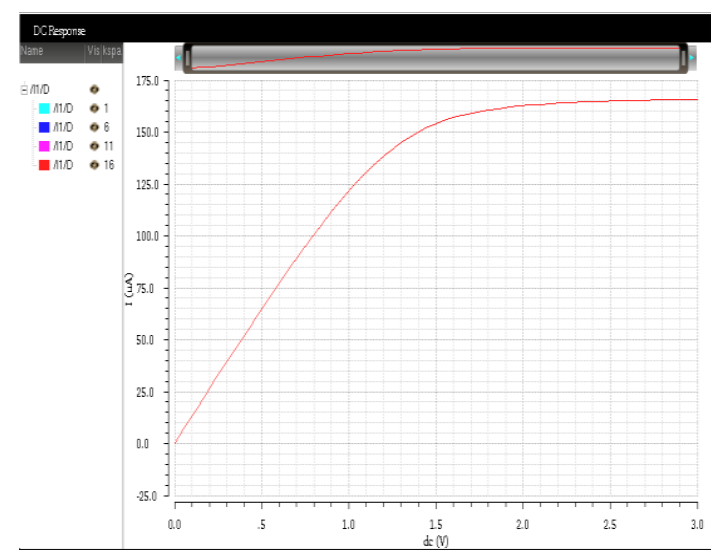

Fig. 6(e) Variation of current conduction with Source/drain spacer dielectric constant

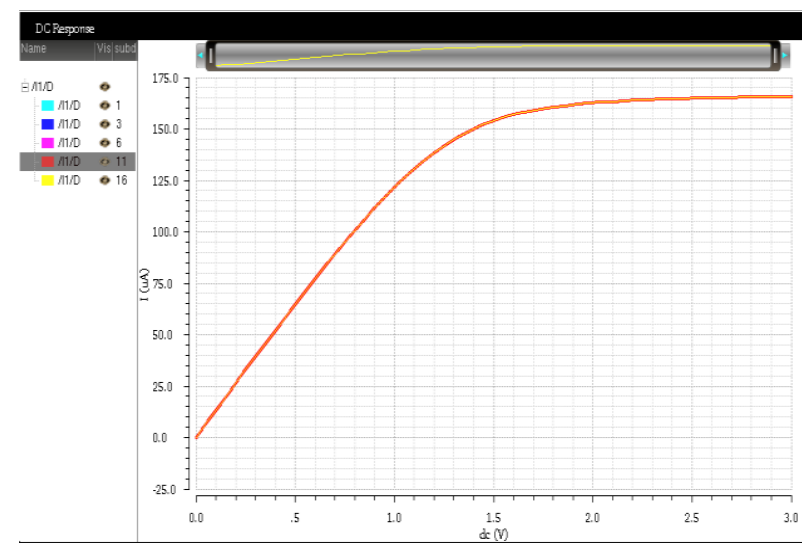

Fig. 6(f) Variation of current conduction with Substrate dielectric constant.

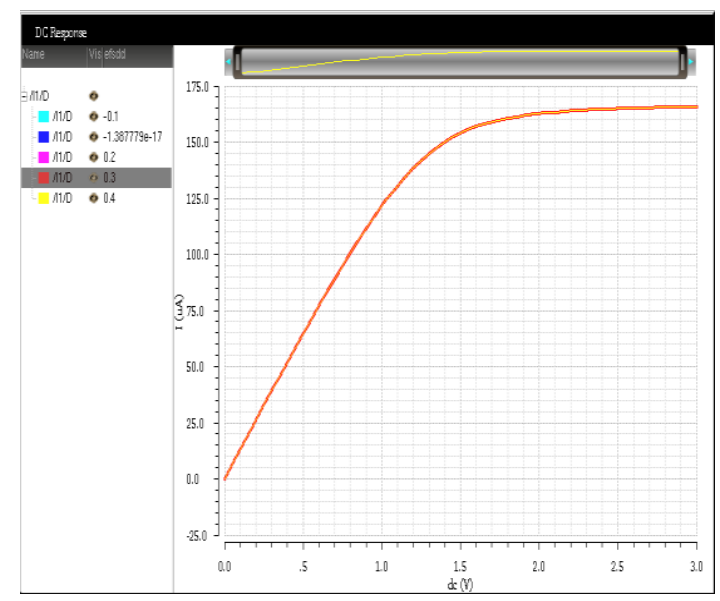

Fig. 6(g) Variation of current conduction with Fermi level to band edge at Source/drain.

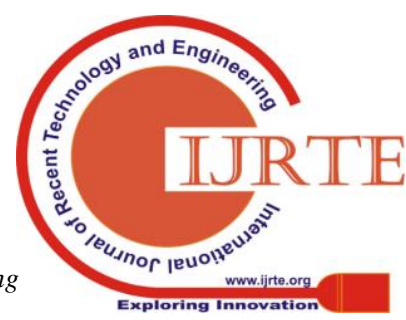




\section{Parameter Analysis of CNTFET}

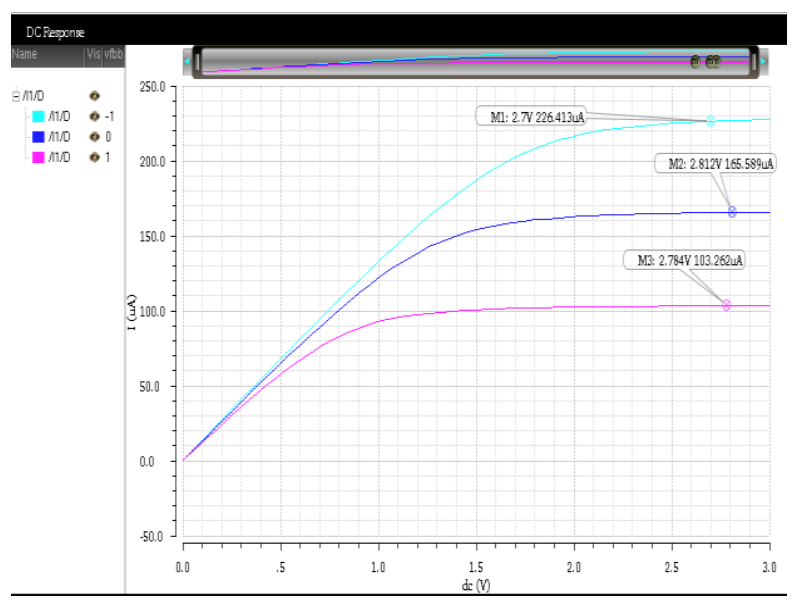

Fig. 6(h) Variation of current conduction with flat band voltage.

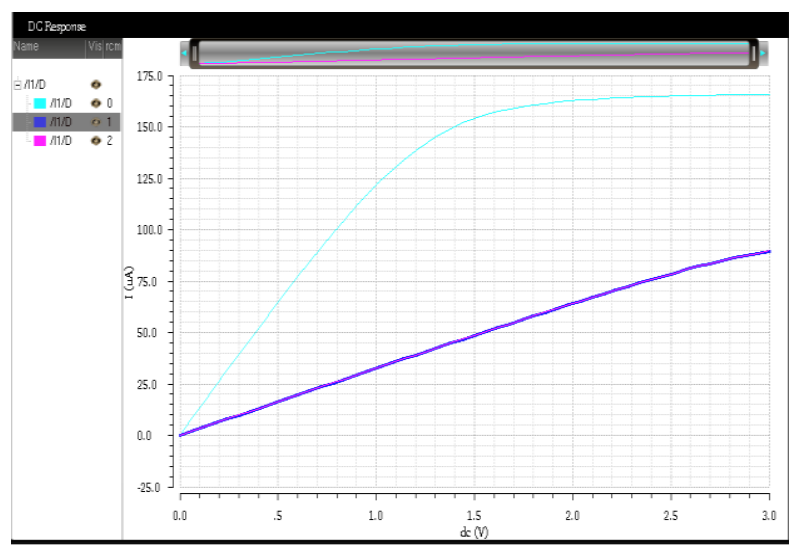

Fig. 6(i) Variation of current conduction with $\mathbf{R}_{\text {cmod }}$

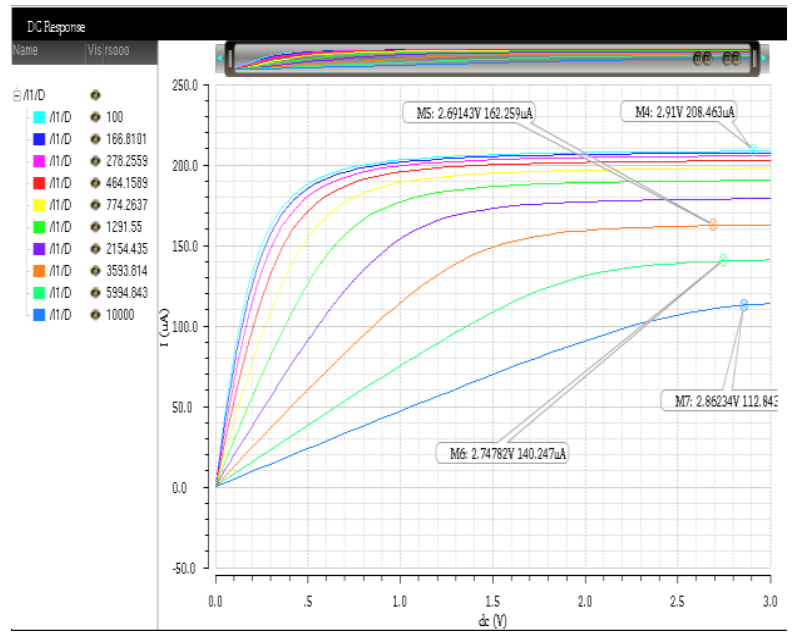

Fig. 6(j) Variation of current conduction with $R_{s 0}$

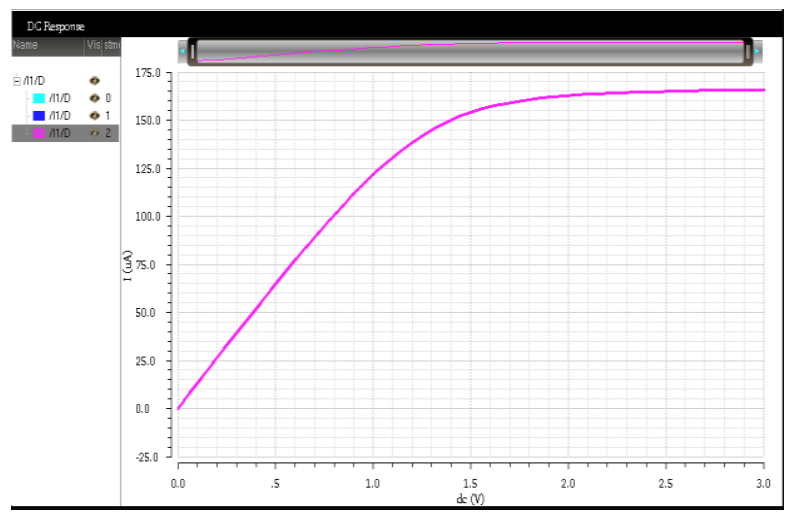

Fig. 6(k) Variation of current conduction with SDTmod

Retrieval Number: B2609078219//2019@BEIESP

DOI: 10.35940/ijrte.B2609078219

Journal Website: www.ijrte.org

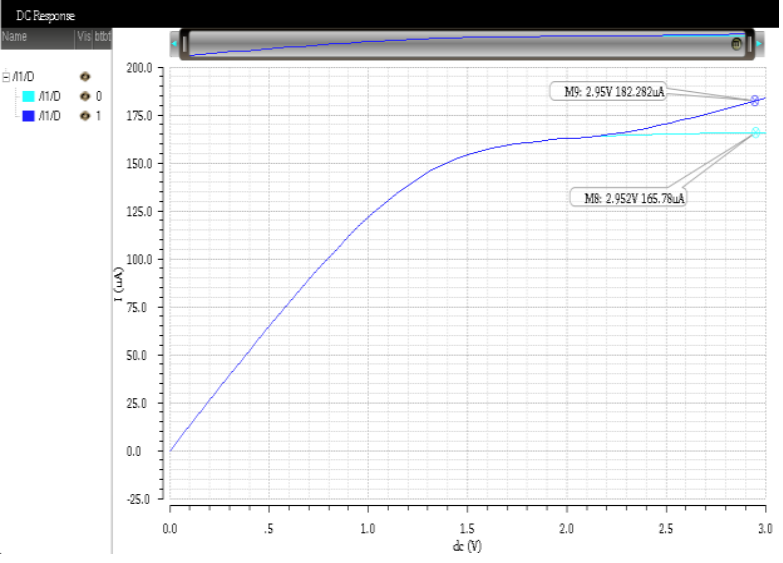

Fig. 6(l) Variation of current conduction with BTBTmod

Simulated results are tabulated as shown below:

Table 1: Vgs Vaiations With Vds $=5 \mathrm{~V}$

\begin{tabular}{|c|c|}
\hline$V_{\text {s Wolts }}$ & low $_{\text {W }}$ \\
\hline 0 & 0 \\
\hline 0.5 & 15 \\
\hline 1.0 & 55 \\
\hline 1.5 & 85 \\
\hline 2.0 & 130 \\
\hline 2.5 & 158 \\
\hline
\end{tabular}

Table 2: $\mathrm{V}_{\text {th }}$ Vaiations With $\mathrm{D}_{\mathrm{CNT}}$

\begin{tabular}{|c|c|}
\hline $\mathrm{D}_{\mathrm{CNT}}$ & $\mathrm{V}_{\text {th }}$ in $\mathrm{V}$ \\
\hline $1 \mathrm{nmt}$ & 0.436 \\
\hline $1.2 \mathrm{nmt}$ & 0.36 \\
\hline $1.4 \mathrm{nmt}$ & 0.311 \\
\hline $1.6 \mathrm{nmt}$ & 0.273 \\
\hline $1.8 \mathrm{nmt}$ & 0.24 \\
\hline $2.0 \mathrm{nmt}$ & 0.22 \\
\hline
\end{tabular}

Device threshold voltage can be varied by changing the CNT diameter using the formula

$$
\mathrm{V}_{\mathrm{th}}=\frac{a\left(V_{\pi}\right)}{\sqrt{3}\left(q D_{C N T}\right)}
$$

Where $\mathrm{a}=2.49 \mathrm{~A}^{\circ}$ carbon to carbon atom distance, $\mathrm{V}_{\pi}=3.033 \mathrm{eV}$ Carbon $\pi-\pi$ bond energy in the tight bonding model,

$\mathrm{q}=1.6 \times 10^{-19} \mathrm{C}$ and $\mathrm{D}_{\mathrm{CNT}}$ is the CNT diameter. $\mathrm{D}_{\mathrm{CNT}}$ can be varied from $1 \mathrm{nmt}$ to $2 \mathrm{nmt}$ to vary the $\mathrm{V}_{\text {th. }}$.

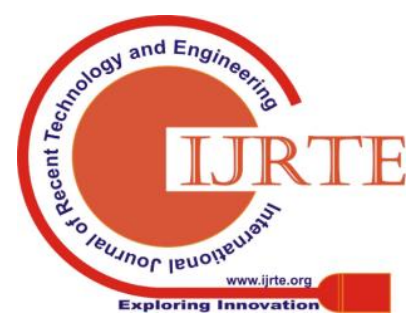


Table 3: Experimental Result With Variations Of Input Parameters.

\begin{tabular}{|c|c|c|c|c|}
\hline SINo. & Parameters & Variations & Current Conduction in $\mu \mathrm{A}$ & Preferred Value \\
\hline \multirow{5}{*}{1} & \multirow{5}{*}{$\begin{array}{l}\text { Gate oxide thickness } t_{0 x} \text { in } \\
\text { nm }\end{array}$} & 2 & 165.737 & \multirow{5}{*}{$2 n m t$} \\
\hline & & 3 & 152 & \\
\hline & & 4 & 145 & \\
\hline & & 5 & 135 & \\
\hline & & 6 & 130 & \\
\hline \multirow{4}{*}{2} & \multirow{4}{*}{$\begin{array}{l}\text { Gate oxide dielectric } \\
\text { constant } \mathrm{K}_{0 \mathrm{x}}\end{array}$} & 3.9 & 74.42 & \multirow{4}{*}{16} \\
\hline & & 11 & 138 & \\
\hline & & 16 & 165 & \\
\hline & & 24 & 198 & \\
\hline \multirow{9}{*}{3} & \multirow{9}{*}{$\begin{array}{l}\text { Physical gate length } \\
\qquad L_{g} \text { in nm }\end{array}$} & 20 & 172.457 & \multirow{9}{*}{$32 \mathrm{~nm}$} \\
\hline & & 30 & 166 & \\
\hline & & 40 & 160.687 & \\
\hline & & 50 & 155.948 & \\
\hline & & 60 & 152 & \\
\hline & & 70 & 148 & \\
\hline & & 80 & 145 & \\
\hline & & 90 & 140 & \\
\hline & & 100 & 136 & \\
\hline
\end{tabular}

\begin{tabular}{|c|c|c|c|c|}
\hline \multirow{5}{*}{4} & \multirow{5}{*}{$\begin{array}{c}\text { Source/drain spacer } \\
\text { dielectric constant } \\
K_{\text {spa }}\end{array}$} & 1 & \multirow{5}{*}{165.737} & \multirow{5}{*}{3.9} \\
\hline & & 3 & & \\
\hline & & 6 & & \\
\hline & & 11 & & \\
\hline & & 16 & & \\
\hline \multirow{5}{*}{5} & \multirow{5}{*}{$\begin{array}{l}\text { Substrate dielectric constant } \\
\qquad K_{\text {sub }}\end{array}$} & 1 & \multirow{5}{*}{165.737} & \multirow{5}{*}{3.9} \\
\hline & & 3 & & \\
\hline & & 6 & & \\
\hline & & 11 & & \\
\hline & & 16 & & \\
\hline \multirow{3}{*}{6} & \multirow{3}{*}{ Vfb-Flat band voltage in V } & -1 & 226 & \multirow{3}{*}{0} \\
\hline & & 0 & 165 & \\
\hline & & 1 & 103 & \\
\hline \multirow{5}{*}{7} & \multirow{5}{*}{$\begin{array}{c}\text { Efsd-Fermi level to the band } \\
\text { edge (ev) } \\
\text { at the source/drain }\end{array}$} & -0.1 & \multirow{5}{*}{165.737} & \multirow{5}{*}{0.358} \\
\hline & & $-1.38 \mathrm{e}-17$ & & \\
\hline & & 0.2 & & \\
\hline & & 0.3 & & \\
\hline & & 0.4 & & \\
\hline
\end{tabular}

\begin{tabular}{|c|c|c|c|c|}
\hline \multirow{3}{*}{8} & \multirow{3}{*}{ Rcmod-Contact mode } & 0 & 165 & \multirow{3}{*}{0} \\
\hline & & 1 & 85 & \\
\hline & & 2 & 85 & \\
\hline \multirow{10}{*}{9} & \multirow{10}{*}{$\begin{array}{l}\text { Rso-User defined series } \\
\text { resistance }\end{array}$} & 100 & \multirow{7}{*}{$150-210$} & \multirow{10}{*}{3300} \\
\hline & & 166.81 & & \\
\hline & & 278.22 & & \\
\hline & & 464.1589 & & \\
\hline & & 774.2637 & & \\
\hline & & 1291.55 & & \\
\hline & & 2154.435 & & \\
\hline & & 3593 & 162 & \\
\hline & & 5994.843 & 140 & \\
\hline & & $10 \mathrm{~K}$ & 112 & \\
\hline \multirow{3}{*}{10} & \multirow{3}{*}{$\begin{array}{l}\text { SDT mod-Source to drain } \\
\text { tunnelling mode }\end{array}$} & 0 & \multirow{3}{*}{165} & \multirow{3}{*}{0} \\
\hline & & 1 & & \\
\hline & & 2 & & \\
\hline \multirow{2}{*}{11} & \multirow{2}{*}{$\begin{array}{l}\text { BTBTmod-band to band } \\
\text { tunnelling mode. 0:off; 1:on }\end{array}$} & 0 & 182.282 & \multirow{2}{*}{0} \\
\hline & & 1 & 165 & \\
\hline
\end{tabular}

Published By: conduction. current conduction

\section{REFERENCES} Systems (Volue:31, Issue: 4 ) April 2012. current research. Sep 2017. Aug 2009. circuits, IEEE International conference 2011. and preferred values is mentioned as it finds common current

\section{CONCLUSION}

The parameter analysis of the CNTFET done using cadence virtuoso and simulated using Spectre model. Preferred value for the CNTFET have been compared with the suggested value of VS-CNTFET and obtained values were tabulated. Tabulation shows that the preferred parameter values and suggested values are giving the similar

1. Jie Zhang,Albert Lin, Nishant Patil, Hai Wei, Lan Wei, H. -S. Philip Wong, Subhasish Mitra. Carbon Nanotube Robust Digital VLSI, IEEE Transactions on Computer-Aided Design of Integrated Circuits and

2. Anitha, N. and Dr. Srividya, P, "Comparative study of different Technologies to replace CMOS Technology". International Journal of

3. A. Khakifirooz, O.M. Nayfeh and D. Antoniadis, A simple semi-empirical short-channel MOSFET current-voltage Model Continuous Acrss All Regions of Operation and Employing only Physica Parameters, IEEE Trans. Electron Devices, Vol..56, no.8, pp. 1674-1680,

4. Jacques L. Athow, Come Rozon ; Dhamin Al-Khalili ; J. M. Pierre Langlois. A CNTFET-based characterization framework for digital 